\title{
A ATIVIDADE ARTESANAL PESQUEIRA VERSUS A AQUICULTURA EMPRESARIAL: as disputas que envolvem a pesca brasileira
}

\author{
LA ACTIVIDAD ARTESANAL PESQUERA VERSUS LA \\ ACUICULTURA EMPRESARIAL: disputas relacionadas con la pesca \\ brasileña
}

\author{
Larissa Tavares Moreno \\ Doutoranda em Geografia pela Universidade Estadual Paulista, Presidente Prudente/SP \\ Bolsista FAPESP \\ larissatavaresmoreno@gmail.com
}

\section{Resumo}

A proposta deste artigo é apresentar os dois projetos em disputa no tocante ao setor pesqueiro brasileiro atual. Iniciando pela discussão da atividade artesanal, sua importância e os sujeitos que compreendem a atividade até o modelo do agrohidronegócio para a pesca, via a aquicultura empresarial. De tal modo a perpassar pela questão dos territórios e territorialidades dos pescadores e pescadoras artesanais e a territorialização do capital nessa atividade. Por fim, destacando a importância e exemplos de (re)existências dos pescadores e pescadoras artesanais em relação ao projeto impulsionado pelo capital. O texto traz reflexões preliminares baseadas em referenciais teórico-conceituais, dados primários e secundários que possibilitam visualizar as particularidades da temática em questão.

Palavras-chave: Pesca artesanal. Aquicultura empresarial. Trabalho. Território.

\section{Resumen}

La propuesta de este artículo es presentar los dos proyectos en disputa en el sector pesquero brasileño actual. Iniciando por la discusión de la actividad artesanal, su importancia y los sujetos que comprenden la actividad hasta el modelo del agrohidronegocio para la pesca, a través de la acuicultura empresarial. De tal modo a pasar por la cuestión de los territorios y territorialidades de los pescadores y pescadoras artesanales y la territorialización del capital en esa actividad. Por último, destacando la importancia y ejemplos de (re) existencias de los pescadores y pescadoras artesanales en relación al proyecto impulsado por el capital. El texto trae reflexiones preliminares basadas en referenciales teórico-conceptuales, datos primarios y secundarios que posibilitan visualizar las particularidades de la temática en cuestión.

Palabras clave: Pesca artesanal. Acuicultura empresarial. Trabajo. Territorio. 


\section{Introdução}

No Brasil o setor pesqueiro é compreendido pela pesca extrativista e a aquicultura, em suas dimensões marinhas ou continentais ${ }^{1}$. No caso da pesca extrativista artesanal esta é uma atividade de fundamental importância social, econômica e histórica no país. Esta apresenta uma heterogeneidade e pluralidade de sujeitos, relações, trajetórias, tipos de apetrechos e embarcações, espécies capturadas, modos de vida, ecossistemas, de dinâmicas espaciais, devido os usos e disputas que tecem seus territórios. E, ao mesmo tempo que representa fundamental relação socioeconômica aos sujeitos, que direta ou indiretamente estão envolvidos, possui um histórico marcante de entraves e injustiças ambientais, territoriais, laborais, e mesmo de invisibilização por parte do Estado brasileiro.

Por sua vez, a aquicultura implica na intervenção humana no processo de criação, produção, alimentação, reprodução, proteção contra predadores, etc. Ou seja, diferentemente da atividade extrativista que depende muito mais da ação da natureza, a aquicultura é uma atividade controlada e planejada pela ação humana, com o propósito de exploração produtiva, econômica e financeira. Sendo assim, a produção de pescados que por muitos anos sempre foi expressivamente proveniente da pesca extrativista, sobretudo artesanal, tem visto a aquicultura aumentar sua participação, inclusive com a ampliação do incentivo financeiro e tecnológico, por exemplo.

Ou seja, mais recentemente temos assistido o incentivo à atividade aquícola ${ }^{2}$, de caráter empresarial, no país. Isto é, tem ocorrido uma nova transformação ${ }^{3}$ do circuito produtivo no setor, ou seja, modificando a relação da produção, circulação, distribuição, consumo e trabalho. Grandes estruturas e empresas têm se organizado para produzir um "adequado desenvolvimento" ao setor, mediante o incentivo à pesquisa, novas tecnologias, rações, aditivos, insumos químicos, maquinário, mão de obra capacitada e qualificada, propaganda, etc., visando os lucros e a consolidação de um mercado de alimentos de pescados.

Compartilhando da opinião de Oliveira (2014) a aquicultura tem sido facilmente enquadrada como mais um ramo do agronegócio, isto é, dentro da perspectiva do capital. Sobretudo, ao se tomar por base o intenso crescimento produtivo, aliado aos avanços tecnológicos e as facilidades de acesso a créditos e políticas públicas. Ao passo que nesse cenário tem-se o incentivo e aumento à especialização, isto é, ao monocultivo da produção 
aquícola, no caso da tilapicultura, que em 2017 registrou 58,4\% do total de piscicultura criada no país (IBGE, 2018). Aliás, isto claramente deve-se ao fato da tilápia ter conseguido demonstrar um rápido crescimento, boa adaptação, bem como ampla aceitação ao consumo nacional. Por isso que a tilápia já vem sendo considerada uma potencial futura commodity brasileira.

É envolto neste cenário que o presente artigo ${ }^{4}$ foi elaborado. Discutiremos os dois modelos em disputa no setor de pescados no Brasil recente. De um lado, o avanço do capital, via o agrohidronegócio, isto é, com o seu projeto de expansão da aquicultura empresarial. Do outro, a atividade artesanal pesqueira.

Vale dizer que nosso intuito é o de trazer, sobretudo, aportes teóricos e conceituais sobre o tema em questão, mas também de dados secundários e alguns elementos primários que estamos produzindo ${ }^{5}$ ao longo de nossas pesquisas (2012 a 2019) em diferentes localidades do país (em Ubatuba no Litoral Norte de São Paulo, Polo Oeste do Paraná e Litoral Sul do Ceará).

Dessa forma, o presente texto se divide em cinco partes. Na primeira parte apresentamos a atividade pesqueira artesanal e os sujeitos. Em seguida comparece o modelo do agrohidronegócio via aquicultura empresarial. Posteriormente, apresentamos o que entendemos como os territórios dos pescadores e pescadoras artesanais e as formas de territorialidade ou até mesmo territorialização do capital, mediante os conflitos e disputas que envolvem os sujeitos e a atividade produtiva de pescados. Na quarta parte discutimos as formas de (Re)Existências dos pescadores e pescadoras artesanais no Brasil frente ao modelo hegemônico do capital pesqueiro-aquícola. E por fim, encontram-se as considerações finais do texto.

\section{Pesca artesanal: uma atividade em disputa}

O trabalho na pesca é uma atividade milenar e de considerável importância mundial para as comunidades envolvidas e para a população em geral. Estima-se que nos últimos anos cerca de 45 milhões de pessoas estão envolvidas com a atividade de captura/cultivo de produtos pesqueiros no mundo todo (FAO, 2009 apud CENTRO DE EXCELÊNCIA PARA O MAR BRASILEIRO, 2012). 
Atualmente estão registrados 1.097 .384 pescadores profissionais no Brasil, sendo que praticamente todos realizam a atividade de maneira artesanal, e apenas $1 \%$ do total são industriais (BRASIL, 2016). Estima-se que do total de pescados produzidos/capturados no país, mais da metade é proveniente da atividade pesqueira artesanal (ASSESSORIA DE COMUNICAÇÃO DO CONSELHO PASTORAL DOS PESCADORES NACIONAL, 2015), sendo que a pesca artesanal marinha é a mais expressiva, se comparada à atividade continental.

Neste sentido, entendemos que os sujeitos que atuam nessa atividade fundamentalmente se constituem em sua realidade vivida, sentida e percebida, são eles próprios que em seu cotidiano, com suas experiências de trabalho e vida social se constituem, formam e (re)definem constantemente o que é ser pescador e pescadora artesanal. Assim, coadunamos com a perspectiva de Cardoso (2001) de que "o pescador artesanal é um sujeito social em processo de redefinição de sua atuação, frente aos usos novos que se impõem aos seus espaços de morada, vida e trabalho".

É assim que enfatizamos o trabalho enquanto conceito fundamental de análise, afinal o elemento identitário do/no/com o trabalho possibilitam aos pescadores(as) um diálogo (e interação) com a água, com a terra, com o ambiente, a família, a comunidade e um dado espaço geográfico. E mesmo diante de desafios, disputas e entraves, a continuidade e a perpetuação dessa atividade laboral tradicional, o sentimento de orgulho, satisfação e identificação os tornam resistentes ainda hoje.

Assim sendo, partimos de que

Antes de tudo, o trabalho é um processo entre o homem e a Natureza, um processo em que o homem, por sua própria ação, media, regula e controla seu metabolismo com a Natureza. Ele mesmo se defronta com a matéria natural como uma força natural. Ele põe em movimento as forças naturais pertencentes a sua corporalidade, braços e pernas, cabeça e mão, a fim de apropriar-se da matéria natural numa forma útil para sua própria vida. Ao atuar, por meio desse movimento, sobre a Natureza externa a ele e ao modificá-la, ele modifica, ao mesmo tempo, sua própria natureza. (MARX, 1996, p.297)

Em outros termos,

O trabalho transforma os meios naturais com seus diferentes valores de uso em meios sociais de existência, realizando o salto de qualidade da natureza natural (dita primeira natureza) em natureza socializada (dita segunda natureza) mediante o qual o homem se transforma de história natural em história social e transforma a história social em história natural autopoeticamente. Relação trans-histórica, pois, na qual homem e natureza se movem reciprocamente numa dialética de interioridade-exterioridade em que o homem transforma a si 
mesmo, hominizando-se, no mesmo ato que transforma a natureza, historizando-a. (MOREIRA, 2016, p.115)

Na geografia do trabalho ${ }^{6}$ é comumente utilizada a expressão metabólica, que significa justamente essa mediação do ser social com a natureza/espaço/território através do trabalho. Logo, é pelo trabalho que o ser natural torna-se um ser social, e por sua vez, demarca sua identidade, seu modo de vida, sua subjetividade e objetividade. Afinal, segundo Marx (1996) o trabalho é condição para a existência social, ou seja, é um momento fundante da vida humana (processo de humanização).

Contudo, sob o capital essa finalidade perde-se ao tornar-se mercadoria. Assim, o trabalho humano converte-se em trabalho expropriado, alienado. Aliás, tem-se a “alienação no lugar de identidade, valor de troca no lugar de valor de uso, predação no lugar de consumo humano, tais são as expressões de concretude de relação homem-meio sob o capital." (MOREIRA, 1982, p. 205).

Essa separação histórica da sociedade e natureza iniciou-se com a acumulação primitiva, isto é, a partir da separação do ser social de seus meios de produção atuado pelo capital, e com isso perdeu-se, para Moreira (1982), a totalidade homem-meio.

Deste modo, é preciso desvendar os esquemas de dominação e controle social que agem sobre as diferentes formas de trabalho. É por isso que entendemos como necessário se (re)dimensionar a discussão do trabalho e, consequentemente, dos sujeitos trabalhadores. Até mesmo porque, embora o assalariamento seja ainda uma das formas predominantes nas relações de produção sob o sistema capitalista, há, também, como própria necessidade do capital que outras formas e dinâmicas se realizem para que o sistema se mantenha.

Partimos do pressuposto que os(as) pescadores(as) artesanais também devem ser entendidos como trabalhadores(as) que compõem a classe trabalhadora. Contudo, estes sujeitos devem ser vistos sob a luz de suas particularidades e da trama de relações expressas territorial e temporalmente.

É preciso, segundo Thomaz Júnior (2009), fazer a crítica e autocrítica dos limites teóricos-científicos postos, a fim de que possamos alcançar a emancipação do capital. Para isso é preciso olhar atentamente para a dialética do trabalho expressa geograficamente no Brasil, que se revela constante e continuamente em movimento, através das manifestações de resistências e conflitos com o modelo de desenvolvimento 
capitalista. É preciso estar atento à totalidade viva do trabalho como diria Mészáros (2002).

Neste sentido, no caso da pesca artesanal a natureza oferece aos sujeitos as condições de existência e reprodução. Sendo que a interação do pescador com o meio ambiente se dá através da mediação do trabalho. Este trabalho, por sua vez, conforme Marx (1996) atua sobre a natureza transformando-a, e ao mesmo tempo este homem que trabalha é transformado por seu trabalho, produzindo-se assim uma relação dialética.

Diante do exposto, quanto aos pescadores(as) artesanais, a produção do pescado é um meio para a subsistência ou um objeto de trabalho destes trabalhadores indicando um estágio de produção na qual o ser social e seu trabalho se confundem com as condições naturais da produção. E diante disso o trabalho não entra como capital nessa relação. $\mathrm{Na}$ medida em que o processo produtivo se dirige principalmente para a produção dos meios de subsistência, para a produção dos valores de uso, o trabalho não é considerado um custo de produção ou um valor de troca (DIEGUES, 1983, p. 92). Diferentemente é a produção capitalista em que as condições naturais passam a ser consideradas como instrumento de trabalho, e consequentemente o pescado se torna uma mercadoria, uma matéria-prima a ser processada industrialmente. Ou seja, a natureza passa a ser entendida como algo externo ao homem, de forma que ela pode ser transformada em um objeto de troca.

No entanto, na pesca artesanal, o trabalho do(a) pescador(a) compreende em sua essência primeira o ato/controle do processo de trabalho e dos meios de sua produção. Aliás, possuem conhecimento acumulado do ofício pesqueiro e não há extração de maisvalia de quem participa do processo de trabalho, tendo em vista seu regime familiar/vizinhança/parceria (DIEGUES, 1983).

Como segunda premissa intrínseca da constituição do trabalho na pesca artesanal, tem-se a práxis-ação dialógica social com a natureza (água, pescados, tempo), com o espaço do qual depende e do qual o forja a partir de sua interação com este. Assim, a pesca artesanal vai muito além de sua funcionalidade econômica (RAMALHO, 2006; D'ÁVILA; TORRES; VARGAS, 2011). Ainda que, sabidamente, grande parte da produção seja destinada à comercialização, isso se dá por uma lógica destinada à reprodutividade da vida, de sobrevivência e manutenção da vida do sujeito pescador(a) e 
de sua família e mesmo organizacional do processo, inclusive para a manutenção e "injeção" de recursos para a próxima saída/lida da pesca.

A essas duas dimensões essenciais e intrínsecas do trabalho da/na pesca artesanal, o desdobramento fundamental e expressivo disso é a constituição identitária do ser pescador e pescadora. O sentimento de orgulho e satisfação em exercer e ser reconhecido como profissionais/trabalhadores, enquanto o pescador e a pescadora, eis então, sem dúvida, o elo de ser e existir enquanto ser social, e como tal, a partir de suas ações e práticas sociais e políticas, de suas lutas e resistências que esses sujeitos expressam suas territorialidades.

O trabalho na/da pesca artesanal possibilita a íntima identidade e relação entre os sujeitos (o ser social), os seus meios de produção e o elo intrínseco com a natureza, possibilitando uma relação singular que "foge à regra" estabelecida pelos imperativos do modo capitalista de produção, mesmo estando ligado às relações mercantis.

Entretanto, como sabemos, o capitalismo é ao mesmo tempo destrutivo e contraditório. Ao ser contraditório possibilita que outros modos de produção coexistam de maneira subordinada e limitada no que tange a existência à própria condição da acumulação do capital. E, por mais que ainda se faça presente a totalidade ser socialnatureza na atividade laboral pesqueira artesanal, as atuações do capital também de uma maneira direta ou indireta implicam conflitos e ações prejudiciais à perpetuação e reprodução dessas comunidades pesqueiras artesanais, seja atuando no trabalho, nos meios de produção ou na natureza - nos seus espaços/territórios, assim caracterizando sua atuação destrutiva.

E é diante das contradições próprias desse sistema que devemos "enxergar" a existência dos(as) pescadores(as) artesanais. Ao mesmo tempo, devemos ter clareza de que a reprodução de vida e trabalho desses sujeitos deve-se historicamente também ao controle territorial do capital.

Aqui vale fazer uma ressalva e destacar que o conceito de controle teve origem na sociologia, estando inicialmente atrelado à noção de ordem e integração social. Para muitos autores as reflexões de Émile Durkheim são consideradas propulsoras do conceito de controle social. Contudo esse conceito foi sistematicamente definido como tal, pela primeira vez, por Edward Alsworth Ross (1901), no qual ele argumenta que o controle 
social não é uma característica natural da sociedade (no sentido biológico ou préexistente), mas sim algo artificial, ou seja, que é socialmente construído.

Entretanto, buscamos em Mészáros (1971) uma definição mais próxima dos nossos estudos na geografia do trabalho. $\mathrm{O}$ autor compreende que a função do controle social, que está relacionado aos sujeitos sociais, foi contudo

[...] alienada do corpo social e transferida para o capital, que adquiriu assim o poder de aglutinar os indivíduos num padrão hierárquico estrutural e funcional, segundo o critério de maior ou menor participação no controle da produção e da distribuição. (MÉSZÁROS, 1971, p.26-27)

Ou seja, a função do controle social mediante as ações do capital visa a efetivação do controle humano (e do trabalho) e da natureza, porém, segundo o autor, no processo de desenvolvimento do capital tem emergido as contradições próprias desse sistema em crise. Assim, a função e o conceito de controle social para Mészáros dizem respeito à necessidade de mudanças sociais, de transformação social e de um "controle social adequado".

Esse controle social é também territorial, isto é, no caso estudado, constatamos que o controle sobre os trabalhadores, ou seja, dos pescadores e pescadoras artesanais em relação ao seu trabalho e à natureza, por exemplo, em relação a todo o processo de trabalho, foi e está sendo colocado em xeque, mediante as novas formas de relação e produção do capital, vide a aquicultura empresarial que é considerada a nova pauta do agrohidronegócio no país. De diferentes formas e lugares, o capital tem expandido o seu controle em relação ao setor pesqueiro nacional, de maneira a produzir uma outra relação para com o trabalho (o ser social) e natureza.

Portanto, o controle social, e também territorial, do capital tem expressões de ordem objetiva e subjetiva, material e imaterial. Contudo, acreditamos que se faz necessária uma transformação dessa lógica imposta pelo capital. Acreditamos ser necessário (e possível) um controle social por parte dos trabalhadores, mediante suas lutas e resistências contra esse processo destrutivo do capital.

\section{A nova pauta do agrohidronegócio: a aquicultura empresarial}

Enquanto que a atividade artesanal pesqueira prioriza a multidimensionalidade (econômica, social, ambiental, política, cultural, etc.), a lógica do capital via a aquicultura empresarial tende a priorizar, evidentemente, a dimensão econômica, fazendo uso de um 
discurso ideológico a fim de difundir a necessidade e importância desse tipo de produção em larga escala no país.

Nesse sentido, é preciso dizer que fazemos uso do conceito de agrohidronegócio por entendermos ser ele capaz de explicar o processo destrutivo do capital no campo, na cidade, em relação à terra e à água, e também com relação aos efeitos direcionados aos sujeitos sociais inseridos nesse processo.

Vale dizer que o conceito de agrohidronegócio foi cunhado pela primeira vez por Mendonça e Mesquita (2007). Esse conceito advém do agronegócio que é o "nome do modelo de desenvolvimento econômico da agropecuária capitalista. Porém, esse modelo não é novo, sua origem está no sistema de plantation, em que grandes propriedades foram utilizadas na produção para exportação." (MENDONÇA, 2010, p.192).

O conceito de agrohidronegócio inicialmente foi compreendido como sendo as formas de uso e exploração da terra pelo agronegócio, em conjunto com os complexos mínero-químicos e metalúrgicos, tendo sido associado também ao chamado "barrageiro", que se refere à produção de energia e reserva de água para irrigação (MENDONÇA; MESQUITA, 2007). Ou seja, o conceito englobava o processo destrutivo do capital no campo e seus reflexos na cidade, assim como as formas de apropriação dos recursos hídricos (superficiais ou subterrâneos).

A partir disso, o conceito de agrohidronegócio foi incorporado por Thomaz Júnior em diversos de seus trabalhos, passando a defini-lo enquanto um modelo de desenvolvimento do capital no campo, desenvolvido por empresas monopolistas (nacionais ou internacionais), que atuam para além da apropriação da terra, mas também e concomitantemente da água. Logo o agrohidronegócio é o controle territorial de forma articulada, que inclusive vai além da degradação dos recursos naturais implicando também na precarização do trabalho, e até mesmo gerando a degradação sistêmica do trabalho (THOMAZ JÚNIOR, 2009; 2016).

Compartilhamos e nos baseamos nessa definição para nossa análise. Contudo, é preciso mencionar que usaremos esse conceito sobretudo pela proporção política que ele nos possibilita para a análise e reflexão do processo que envolve o setor pesqueiro nacional. Além disso, vale lembrar que não podemos esquecer a diversidade e a pluralidade que compreendem o uso do conceito de agrohidronegócio, isto é, existem 
agrohidronegócios, afinal, esse processo se dá em diferentes setores/produtos: soja, cana, carne, peixes, etc.

Diante disso, entendemos que o avanço dos agrohidronegócios no Brasil se dá pela unificação dos interesses dos conglomerados relacionados à produção de commodities, seja agro, químico, alimentar ou financeira, o que gera conflitos múltiplos. De um lado, estão os interesses do capital e do Estado em controlar, negar ou eliminar as resistências dos sujeitos sociais (pescadores artesanais, camponeses, ribeirinhos, por exemplo). Do outro lado, estão os sujeitos sociais em luta, em defesa do seu direito pela água, pela terra, pelo território, territórios estes que estão constantemente em disputa.

É nesse cenário que adentramos no setor de pescados nacional, tendo em vista que o mesmo está, atualmente, passando por um novo processo, isto é, está sendo redimensionado em termos político-ideológicos e econômicos, tendendo a favorecer a territorialização do capital e/ou a territorialidade capitalista nos territórios dos(as) pescadores(as) artesanais e de outras comunidades tradicionais.

No que tange à aquicultura empresarial (que já vinha sendo incentivada antes mesmo dos anos 2000), veremos o claro desejo e desenvolvimento desse segmento, sobretudo nos últimos anos, que deixou de ser um segmento que contribuía no ano de 2003 com apenas $28 \%$ do total produzido, passando para 44\% do total em 2011 (BANCO DO BRASIL, 2010; BRASIL, 2012, 2013).

É perceptível o claro propósito do Estado e do capital em incentivar a expansão da aquicultura no país, a qual obteve um aumento de 350 mil toneladas se comparada à pesca extrativista que cresceu menos de 90 mil toneladas nesse mesmo período de 2003 a 2011 (BANCO DO BRASIL, 2010; BRASIL, 2012, 2013).

Em 2017, a atividade aquícola nacional registrou uma produção de 547,1 mil toneladas, sendo que deste total $88,7 \%$ são provenientes da piscicultura, seguida da carcinicultura com 7,5\%, e o restante é distribuído entre ostras, vieiras, mexilhões, entre outros (IBGE, 2018).

No tocante à piscicultura (485,2 mil toneladas produzidas) a região do Sul do país, notadamente o Paraná, lidera a produção, sendo que 58,4\% da piscicultura é representada pela tilapicultura, que também tem o Sul do país como o maior produtor, com $42 \%$ da criação nacional (IBGE, 2018). As demais espécies com expressividade 
produtiva da criação de peixes são: tambaqui (18,2\% do total), tambacu e tambatinga (8,7\% do total), carpa (3,9\% do total) e outros (10,8\% do total) (IBGE, 2018).

A carcinicultura, por sua vez, tem na região Nordeste a maior produtora com 98,8\% do total (41 mil toneladas), destacando-se o Rio Grande do Norte e o Ceará como maiores produtores, $37,7 \%$ e 28,9\% respectivamente (IBGE, 2018). Já as ostras, vieiras e mexilhões apresentam mais de $98 \%$ de sua produção nos municípios de Santa Catarina (IBGE, 2018).

Em outros termos a tendência atual está pautada em ações que levam a chamada "Revolução Azul", isto é, a potencialização do desenvolvimento tecnológico e produtivo do setor pesqueiro, com vias a expansão aquícola empresarial no território nacional. Ao passo que isso influencia a indústria alimentícia não só nacional, mas também a internacional, as quais geram a produção de uma forma determinada/controlada de produtos/pescados que atendam os interesses do capital. Entretanto, sem se preocupar com a melhoria da qualidade de vida e trabalho das comunidades pesqueiras tradicionais, com a forma de produção incentivada, com o tipo de uso da água usada nesse processo e sobre a qualidade dos alimentos que estão sendo produzidos.

A expressão Revolução Azul passa a ser veiculada referindo-se à possibilidade de expansão produtiva em ambiente aquático para o cultivo de pescados, inclusive sendo inspirada no processo que envolveu a Revolução Verde, que por sua vez marcou a intensificação da produção agropecuária no mundo, sobretudo a partir da década de 1950/60, diante do uso de máquinas, fertilizantes, pesticidas, pouca variação de sementes e o uso de extensas áreas de terras para a monocultura. Segundo Wojciechowsk (2014), esse termo foi cunhado ainda nos anos 70 pelo Banco Mundial referindo-se à produção/cultivo intensivo de espécies aquáticas.

No contexto brasileiro, Sussel (2010) argumenta que a Revolução Azul tem pouco a pouco expandido e ocupado mais espaço, sendo que a tilapicultura é o segmento mais importante desta revolução. Além disso, para o autor a tecnologia é o diferencial nesse processo aquícola, sendo que isso se desenvolveu no caso da criação de tilápias, na região Sul do país, mais especificamente no Paraná.

Assim, é perceptível o quanto vem se investindo nesse setor no Brasil a fim de que ele possa estar entre os sete maiores produtores do mundo, de maneira a conquistar mais destaque do que as produções bovinas e avícolas. 
Como se não bastasse esse cenário, o setor pesqueiro nacional tem passando ultimamente, por intensas modificações institucionais, como foi o caso da extinção do MPA em outubro de 2015, passando suas atribuições ao Ministério da Agricultura, Pecuária e Abastecimento (MAPA), entretanto entre março de 2017 e abril de 2018 a Secretaria de Aquicultura e Pesca (SAP) vinculou-se ao Ministério da Indústria, Comércio Exterior e Serviços (MDIC), sendo que atualmente está vinculada à Secretaria Geral da Presidência da República. Isto só reforça a tentativa de dar continuidade aos interesses de expansão do setor em termos empresariais, o que, por outro lado, tende a comprometer e prejudicar o segmento artesanal.

Dessa maneira, entendemos que a aquicultura empresarial está inaugurando uma "nova" ordem sociometabólica da produção pesqueira. No que se refere ao entendimento sobre o sistema sociometabólico nos baseamos na leitura de Mészáros (2002), que por sua vez se apoiou no conjunto das obras de Marx, que define esse processo como o intercâmbio (social) metabólico dos seres sociais (humanidade) com a natureza e dos indivíduos particulares entre si. Sendo assim, atualmente o sistema sociometabólico está dominado pela lógica do capital, e que por sua vez esse sistema deixa de representar o intercâmbio produtivo dos seres sociais com a natureza e com si mesmos, para submeter os sujeitos e o trabalho a seu controle e as suas necessidades e interesses de produção/reprodução.

Portanto, o setor pesqueiro está "vivenciando uma reestruturação produtiva, saindo da pesca extrativista para a aquicultura. A reestruturação produtiva tem como pano de fundo a narrativa dogmática da revolução azul". (WOJCIECHOWSKI, 2014, p.59, grifo do autor).

Entretanto, conforme salienta Oliveira (2011), assim como outras formas de produção e cultivo intensivo, a aquicultura causa impactos negativos.

O desenvolvimento da aqüicultura brasileira tem apontado para algumas questões relativas à sustentabilidade dos cultivos, em especial mediante a introdução de espécies exóticas, o uso das águas, o uso das áreas de manguezais para atividades aquícolas, dentre outros impactos considerados negativos no desenvolvimento da atividade.

Pensar em uma aqüicultura que caminhe para a sustentabilidade não está relacionado apenas aos aspectos ambientais dos cultivos, mas pressupõe uma abordagem que leve em consideração aspectos econômicos, tecnológicos, sociais, culturais, territoriais e político-institucionais. Refletir sobre a integração entre estas distintas dimensões permite vislumbrar um desenvolvimento integrado do setor, dirimindo os conflitos de uso dos recursos 
e entre os distintos agentes produtores do espaço geográfico. (CARDOSO, 2009, p.134).

Por conseguinte, Oliveira (2011) alerta que é preciso entender que a expansão acelerada da aquicultura deve ser acompanhada de cautela não só pelos impactos ambientais, mas também pelas comunidades e trabalhadores(as) envolvidos nesses ecossistemas, e que não seja pensada apenas para servir aos anseios de "setores da burguesia para manter em curso a acumulação do capital" (OLIVEIRA, 2011, p.84).

Diante dessa lógica expansiva do sistema sociometabólico do capital, veremos, cada vez mais, a separação/eliminação do controle territorial dos trabalhadores pescadores e pescadoras em relação a seu trabalho, produção, consumo e circulação. Posto isto, nota-se a fragmentação de todos os elementos que compõem o processo, e como tal, tem-se mais incisivamente o avanço do capital, controlando a natureza e os trabalhadores.

\section{Os territórios dos(as) pescadores(as) artesanais e a expansão territorial capitalista}

O debate sobre o conceito de território é fundamental para nos auxiliar a compreender os processos que envolvem o setor de pescados nacional. Para tanto, vale explicar que a orientação metodológica de compreensão do conceito de território parte da relação indissociável entre espaço, tempo, sujeito e território.

O espaço surge através da intencionalidade social, onde o ser social por meio de seu trabalho apropria-se do espaço natural transformando-o em um espaço geográfico.

\footnotetext{
Não há produção que não seja produção do espaço, não há produção do espaço que se dê sem o trabalho. Viver, para o homem, é produzir espaço. Como o homem não vive sem trabalho, o processo de vida é um processo de criação do espaço geográfico. A forma de vida do homem é o processo de criação do espaço. Por isso a geografia estuda a ação do homem. (SANTOS, 2012, p.9697)
}

Consequentemente, se faz necessário compreendermos que a relação do homem com a natureza é sempre dinâmica e progressiva, onde "A natureza vai registrando, incorporando a ação do homem, dele adquirindo diferentes feições, que correspondem às feições do respectivo momento histórico." (SANTOS, 2012, p. 97).

Entende-se que este espaço é " [...] formado, de um lado, pelo resultado material acumulado das ações humanas através do tempo, e, de outro lado, animado pelas ações 
atuais que hoje lhe atribuem um dinamismo e uma funcionalidade." (SANTOS, 2004, p.106). Ou seja, o espaço está em constante processo de transformação, sendo, portanto, produzido social e historicamente. Logo, a noção de espaço é inseparável da ideia de tempo.

Do mesmo modo, o espaço é indissociável do sujeito, afinal este "sujeito histórico é aquele que participa das determinações de seu espaço, é o que pratica ação, participa da luta contra os que querem transformá-lo em massa, contra os que o querem separado de si mesmo." (FERNANDES, 1991, p. 33).

Além disso, o espaço é também indispensável para a apropriação e produção do território, pois o espaço é a materialização da existência humana, e enquanto tal o espaço é um a priori, e o território é um a posteriori (FERNANDES, 2008; 2009).

Assim, por território, entende-se o produto (histórico) das relações estabelecidas entre a sociedade e a natureza, e a condição para a reprodução social, onde a sociedade transforma (humaniza) essa natureza (o espaço) (SAQUET, 2007).

Nesse sentido, os sujeitos sociais em sua mediação com a natureza são centrais para a efetivação dos territórios e suas territorialidades, daí que as relações sociais são fundamentais na análise e compreensão do território (SAQUET, 2015).

Contudo, será através do entendimento da disputa enquanto elemento essencial da compreensão do conceito de território, conforme defendido por Fernandes (2009), ao considerar o território não como uno, mas diverso, e portanto com conflitualidades, é que nos basearemos mais propriamente. Afinal coadunamos com o entendimento de que não há território sem conflitualidade, portanto o território tem relação com a luta de classes.

Os territórios são materiais e imateriais, e apresentam várias dimensões: social, cultural, ambiental, econômica, política, etc., o que vale dizer que o território não é fração, mas totalidade. Do mesmo modo, é preciso não se esquecer que território está relacionado à história, é relacional, pluriescalar. O território é condição de possibilidade, resistência e liberdade, mas também de dominação, controle e expropriação.

Em nossa pesquisa estamos atentos aos processos relacionados aos sujeitos sociais e ao seu trabalho, este enquanto relação social, e envolvido nas contradições da relação capital-trabalho-Estado na qual é envolto numa trama de usos, disputas e conflitos que permeiam o espaço de produção e reprodução desses sujeitos, ou melhor, do(s) território(s) dos pescadores e das pescadoras artesanais. Territórios esses que a seguir 
destacamos, assim como o processo de disputa e expansão das territorialidades capitalistas.

\section{$\mathrm{O}(\mathrm{s})$ território(s) dos(as) pescadores(as) artesanais}

A atividade pesqueira é uma modalidade do uso do espaço aquático (produção e apropriação), terrestre (como por exemplo: o espaço de moradia e para comercialização do pescado) e com interferências da natureza/fenômenos atmosféricos (CARDOSO, 2001). Mas também com implicações advindas da especulação imobiliária, turística, a poluição, a urbanização, políticas públicas, enfim por um conjunto de interferências que direta ou indiretamente refletem para a relação, o uso e a produção do espaço na qual também estão os sujeitos pescadores e pescadoras artesanais (MORENO, 2017).

Por isso o território vai além do entendimento, enquanto o recurso pesqueiro a ser apropriado/explorado ou viés econômico, é também onde os laços familiares e de trabalho se encontram e se reproduzem, onde emanam lutas e reconhecimento/pertencimento a uma identidade. Ou seja, antes de tudo o território devese às relações sociais, sendo, portanto, relacional, vivido e apropriado pelos sujeitos sociais, ou seja, é uma categoria da prática, para além de uma categoria analítica e político-normativo.

A escolha do conceito de território se justifica tanto por ser capaz de explicitar os nós e diferentes manifestações que ocorrem espacialmente e que direta ou indiretamente trazem rebatimentos aos pescadores(as) e suas comunidades. Em outras palavras, para analisarmos os conflitos e resistências que os envolvem, compreendemos que esses se expressam no/do/pelo(s) território(s) dos pescadores e pescadoras artesanais. Esse conceito é capaz de explicar a identidade, autonomia e relação tradicionalmente expressa nos espaços territorializados por esses sujeitos sociais, ou seja, visa dar legitimidade e priorizar os sujeitos.

O território deve ser compreendido como condição de possibilidade, existência, resistência e liberdade. Mas ao mesmo tempo em que é um espaço de liberdade, é também de dominação e expropriação por parte das ações do capital.

Devemos lembrar que esses territórios, como adverte Almeida (2008), vai além do sentido estático e fixo, isto é, de se reconhecer apenas a ocupação e usos permanentes, 
e é preciso também alargar essa compreensão para entender a mobilidade intrínseca das atividades exercidas por esses sujeitos sociais. Assim como é necessário compreender a dimensão simbólica, imaterial que os sujeitos têm com o território. Do mesmo modo, esses territórios são descontínuos, ou seja, eles são marcados por espaços nem sempre usados o ano todo, a exemplo das áreas de estuário, isto é, os territórios pesqueiros.

Por outro lado temos a lógica expropriante e degradante do capital, que insere outras dinâmicas (de diferentes formas e magnitudes) na relação trabalho e com/no território. Ou seja, o conflito é iminente nesse processo.

Neste sentido, conforme expomos em nossas pesquisas anteriores (MORENO, 2017), apostamos na existência de território(s) dos pescadores e pescadoras artesanais. Esses territórios (materiais e imateriais) de uso comum/coletivo compõem-se da terra para a água ou vice-versa.

Nos territórios da/na/em terra se dá a reprodução das condições de existência dos sujeitos, isto é, é onde ocorre a reprodução do modo de vida (social, cultural, política e economicamente) desses(as) pescadores(as) e suas comunidades tradicionais. É onde se realiza a comercialização, sendo, portanto, também um espaço de trabalho e de relações sociais. Na terra, é também o espaço de moradia. É onde existem as sedes das organizações sociais e políticas, como as Colônias de Pescadores, as Associações e Sindicatos, enfim elementos esses e tantos outros que compreendem a dimensão material desse(s) território(s).

Na dimensão imaterial nos territórios da/na/em terra estão, por exemplo, as identidades, os saberes, as crenças e os elementos religiosos e simbólicos desses sujeitos e suas comunidades.

$\mathrm{Na}$ interface dos territórios, seja na terra e na água, estão a praia, o mangue, a floresta, as matas ciliares, enfim, os espaços necessários para a manutenção da atividade artesanal pesqueira, pois é onde se encontram os ranchos de pesca, onde se possibilita o acesso à água, onde se elabora e repara os instrumentos de pesca, onde também estão presentes a espiritualidade, as crenças e histórias.

No tocante aos territórios na/da água em termos materiais, podemos destacar, sobretudo, o caráter de ser o espaço prioritariamente de trabalho, onde estão os chamados territórios pesqueiros, isto é, os locais onde a pescaria/coleta dos pescados é realizada, seja em água doce ou salgada, e por assim ser, esses territórios nem sempre são contínuos, 
pois na verdade eles são descontínuos e móveis, já que em determinada época do ano onde se pescou num dado local, em outra época não se pescará. Mas também em alguns casos, sobre a água também está o local de moradia. Quanto à dimensão imaterial podemos mencionar o conhecimento tradicional, os saberes na/da lida pesqueira, que são transmitidos de geração para geração.

Ou seja, percebe-se que esses territórios são para além de fixos, são constituídos pela mobilidade desses sujeitos. São territórios descontínuos, relacionais, historicamente constituídos e reproduzidos. São formados por intencionalidades, multidimensões e são pluriescalares, pois atuam e têm interferência de ações de diferentes escalas (local, regional e até mesmo nacional). São territórios coletivos de autonomia e liberdade, mas igualmente são de disputas.

Conforme apontamos em Moreno (2017), nos territórios em terra estão presentes (direta ou indiretamente) os conflitos, sejam eles, por exemplo, mediante a urbanização, o turismo, a especulação imobiliária, as restrições de acesso à água, as Unidades de Conservação, etc. Do mesmo modo, as conflitualidades estão presentes nos territórios, na água. Seja com as embarcações de passeio e pesca amadora/esportiva, com os navios de cruzeiros, as políticas restritivas à pesca (áreas delimitadas/restritas à pesca), as políticas de incentivo à aquicultura empresarial, as poluições, etc.

Enfim, estes territórios são territórios em disputa, nos quais o capital os vê como espaços vazios e, consequentemente, como possibilidade de lucro, exploração e acumulação. Deste modo, o direito ao território é negado às comunidades tradicionais e artesanais, que se veem constantemente em disputa com os grandes empreendimentos, com a especulação imobiliária, o turismo, a construção de hidrelétricas/barragens, a implantação de parques aquícolas e dentre tantas outras formas de materialização do capital.

A seguir, apresentamos o exemplo mais recente da expressão territorial da lógica capitalista que nega o direito ao território, ao trabalho e o modo de vida artesanal pesqueiro mediante a constituição do capital pesqueiro-aquícola, materializado pela aquicultura empresarial.

\section{O capital aquícola: alguns elementos da territorialidade e territorialização}


Nos territórios (em terra e na água) dos pescadores e pescadoras artesanais (e das comunidades tradicionais) estão presentes os conflitos, as disputas e os interesses do capital, e não é somente nessas diferentes formas de expressão e localização (isto é, nos sistemas produtivos, em diferentes áreas terrestres, aquáticas, com relação às represas/hidrelétricas, parques aquícolas, etc.), mas também com relação aos trabalhadores, com os pescadores e pescadoras, camponeses, ribeirinhas, etc.

Dessa maneira, a nosso ver, existe a territorialidade capitalista adentrando nos territórios dos(as) pescadores(as) artesanais e comunidades tradicionais. Apoiando-se nas reflexões de Fernandes (2008; 2009), entendemos a territorialidade enquanto as expressões/manifestações/ações/práticas/usos/intenções que um dado sujeito/classe, isto é, uma relação social que emanam/produzem em um dado território, podendo ser "soberano" ou não. Assim como, pode se realizar no território desses mesmos sujeitos/classe ou podem se reproduzir em outros territórios, de outros sujeitos/classe.

Os territórios dos(as) pescadores(as) artesanais (e de outras comunidades tradicionais envoltas no setor pesqueiro) são e estão constantemente marcados pelas disputas e interesses do modelo sociometabólico do capital, que por sua vez tende a buscar formas de expandir nesses territórios e controlar, explorar e subordinar o trabalho desses sujeitos e a produção (e também a distribuição, circulação e consumo) a seus interesses. A lógica de reprodução sociometabólica do capital visa outra relação para com os recursos naturais, para com a vida e o trabalho.

A proposta atual, mediante o avanço da aquicultura empresarial, estabelece "novas" formas de controle territorial, de maneira a interferir no trabalho e na natureza, trazendo rebatimentos aos sujeitos e aos seus territórios. Daí que os conflitos se afloram, seja pela terra, pela água, em relação ao trabalho e ao território. Conflitos que envolvem as formas de uso, ocupação, gestão, direitos territoriais e laborais, por exemplo.

A aquicultura no Brasil conta com um ambiente favorável a sua expansão, seja pela forte demanda do mercado externo, ganhos econômicos rápidos aos que investem nessa atividade, pesquisas e tecnologias em constante processo de implementação, autorização da utilização de águas da União para fins de aquicultura, enfim uma série de fatores que comungam para a expansão desse capital pesqueiro-aquícola.

Para trazer alguns exemplos desse processo e avanço do capital, ou seja, a materialização dessa territorialidade capitalista, ilustraremos alguns casos. A "reforma 
aquária"7, por exemplo, ilustra muito bem essa territorialidade capitalista mediante o avanço da produção aquícola empresarial no país. Essa proposta política e ideológica para o setor pesqueiro foi utilizada pelo extinto Ministério da Pesca e Aquicultura (MPA), com o propósito de possibilitar a ampliação e desenvolvimento da criação de pescados, de maneira a levar o país a ser um dos maiores produtores de pescados mundiais. Porém em busca do moderno e progresso, esse processo se fez à custa dos pescadores e pescadoras artesanais e demais comunidades tradicionais que se viram dependentes e sujeitos a esse processo aquícola, e os próprios recursos. Isto é, a água vista como abundante para a instalação dos parques aquícolas foi sendo privatizada, seguindo assim a tendência do neoliberalismo, de maneira a difundir o mais novo ramo industrial da pesca: a aquicultura em seus moldes empresariais.

Dessa maneira, entendemos que a "reforma aquária" na realidade representa uma contrarreforma do Estado brasileiro, afinal, como esclarece Coutinho (2010), esse tipo de processo tem feito o uso do termo reforma de maneira equivocada, pois o que se expressa é a destruição dos direitos anteriormente existentes, sendo assim, esse processo deve ser compreendido como contrarreforma e não enquanto reforma.

A reforma aquária se mostra essencialmente como um modo de
desregulamentar a exploração dos recursos naturais, facilitando a
expansão/diversificação de investimentos do capital. Portanto, traduz-se em
mais uma estratégia para obter "mais do mesmo": expansão de nichos de
mercado em tempos de crise do capital. Com essa proposta, o Estado brasileiro
fortalece a lógica que reverte um bem comum (a água) ao caráter de mercadoria
- um movimento que favorece a expansão do hidronegócio que significa,
"literalmente, o negócio da água". (SANTOS; ACIOLY, 2015, p.268 - grifo
dos autores).

A expressão "reforma aquária", portanto, foi utilizada pelo Estado no sentido totalmente ideológico de se apresentar como algo bom e necessário ao setor pesqueiro, mas que de fato está fundamentado por elementos destrutivos e regressivos para o conjunto dos trabalhadores, sendo assim trata-se não de uma reforma, mas sim de uma contrarreforma do Estado.

No Paraná, temos assistido a um outro caso deste processo de expansão do capital aquícola. Este estado é o pioneiro no cultivo de tilápias no país e tem se tornado um importante polo produtivo em crescente desenvolvimento, apresentando atualmente dois importantes polos produtivos, um ao Norte e outro a Oeste do estado (BROL; MOLINARI, 2017). Boa parte da piscicultura neste estado tem visado a produção 
verticalizada, e desta forma, com vias de promover um rápido desenvolvimento, os pequenos produtores vão paulatinamente sendo levados a se inserir neste modelo de integração. Assim, na outra ponta do processo vemos as grandes empresas lucrando cada vez mais. Ou seja, esse modelo aquícola empresarial visa "concentrar capital e meios de trabalho em poucas mãos" (RAMALHO, s/d, p. 6), expropriando territorialmente e/ou controlando as atividades e espaços das comunidades extrativistas, bem como pequenos produtores, camponeses e demais comunidades tradicionais.

Do mesmo modo, esse modelo faz uso e abuso do "metabolismo quimificado dessa atividade com a natureza, contando com o servil e essencial apoio científico para a realização de sua produção em série”. (RAMALHO, 2015 p. 536). Aliás, quanto a este quesito de aporte científico, no Paraná também isto é evidente. A territorialidade do capital aquícola se fortalece com o advento dos cursos de nível técnico e superior relacionados à aquicultura que possibilita a formação de profissionais que dão suporte técnico, sendo que nesse estado existem ao menos oito cursos voltados a esse processo (sejam eles de nível técnico, graduação ou pós-graduação) todos oferecidos por instituições de ensino público de esfera estadual e federal.

Outro exemplo da territorialidade capitalista é a tentativa de negar e eliminar a autonomia dos pescadores e pescadoras artesanais, já que a aquicultura cria diferentes formas de dependência dos sujeitos sociais ao longo de sua cadeia produtiva, desde os insumos e rações, a forma de produção/criação aquícola, chegando até a forma de comercialização dos produtos, por exemplo (RAMALHO, 2014).

Outra dinâmica de expansão do capital ocorre, por exemplo, na apropriação ilegal e na degradação de manguezais, aliado ao cerceamento do direito de ir e vir dos pescadores artesanais que utilizam esses espaços para pescar/coletar e também como caminho para a pesca marítima, como é o caso de várias comunidades e áreas de mangue no litoral cearense.

Conforme temos observado em nossas incursões a campo, bem como entrevistas realizadas, no Ceará, os pescadores e marisqueiras estão cada vez mais sendo privados de seus direitos, de seus territórios, de suas práticas e usos tradicionais. Nota-se de forma intensiva e sistemática, a destruição dos manguezais, o desmatamento de mata ciliar, escavações e terraplanagem do ecossistema, privatização e barramento de cursos d'água, expulsão de populações extrativistas, salinização de aquíferos, etc., que são cometidos 
por empresas de carcinicultura, ou também conhecidas como, o "manto verde da destruição" (MEIRELES; QUEIROZ, 2011).

Assim a carcinicultura ocorre mediante a exclusão das comunidades tradicionais, através da ocupação de viveiros de camarão nas áreas de morada e atividades usadas para pesca/coleta/mariscagem, ou seja, os "territórios ancestralmente utilizados foram incorporados ao processo de produção de camarão em cativeiro" (MEIRELES; QUEIROZ, 2011, p. 73).

E por mais que a carcinicultura afirme gerar muitos empregos e renda, esta tende a obedecer à lógica do agronegócio, buscando primeiramente a lucratividade, oferecendo poucas oportunidades de emprego para as comunidades locais, e estas quando ocorrem se dão mediante trabalhos temporários, mal remunerados e que em muitos casos não oferecem nenhum tipo de segurança ao trabalhador (BATISTA; TUPINAMBÁ, 2004).

E assim, antes o que era território dos pescadores e pescadoras artesanais passa a sofrer com as interferências e a ser desestruturado pelo capital pesqueiro-aquícola, isto é, pela lógica aquícola empresarial, alterando a dinâmica de produção e controle do trabalho, da comercialização e consumo. E infelizmente quando essa territorialidade capitalista se faz tão marcante e sufocante ela tende a transformar esse local em um espaço privado, isto é, para a realização do capital, para a produção e reprodução capitalista de cultivo aquícola, e assim o que tem se observado atualmente é o processo de espacialização e territorialização do capital pesqueiro-aquícola. Explica Fernandes (2008; 2009) que a espacialização representa a efetivação, o movimento concreto das ações e sua reprodução no espaço/território; e, por sua vez, o processo de territorialização é a expansão de territórios, seja de maneira contínua ou descontínua.

A isso, os pescadores e pescadoras e demais comunidades tradicionais têm seus direitos negados e passam a ter que se sujeitar a trabalharem nessas empresas aquícolas, a se destinarem a outras atividades produtivas, ou até mesmo a buscarem em outros lugares formas de se manter na atividade pesqueira artesanal.

\section{As (re)existências contra o modelo hegemônico do capital}

Como vimos ao longo deste texto, nas últimas décadas a aquicultura empresarial tem crescido significativamente no Brasil, implicando novas dinâmicas, práticas, relações 
para com a natureza, o trabalho e os trabalhadores/sujeitos sociais envoltos neste setor. Ao resultar, em muitos casos, uma expansão desordenada e que desconsidera a gestão e qualidade da água, os impactos socioambientais, as implicações territoriais de suas instalações e os sujeitos/comunidades que nestes espaços habitam/pescam/coletam.

Vale dizer que não são apenas os pescadores e pescadoras artesanais que são afetados por esse processo, mas, sim, será toda a sociedade em geral que terá (e já está tendo) implicações no acesso aos recursos naturais, assim como reflexos nos alimentos consumidos.

Enfim, essa lógica de expansão da aquicultura representa o mais novo mecanismo do agrohidronegócio brasileiro, que na prática suscita rebatimentos diretos aos pescadores e pescadoras artesanais, comunidades tradicionais, mas também para toda a sociedade. É preciso, pois, combater, lutar e (re)existir a esse modelo que degrada e expropria.

Vale dizer que, segundo Porto-Gonçalves (2006), as resistências devem ser compreendidas, sobretudo, através do protagonismo dos sujeitos, que são ativos e agem, e que não somente resistem, mas também e principalmente re-existem. Outra definição foi proposta por Pelá e Mendonça (2010), segundo eles as (re)existências representam

[...] um processo de permanência, modificada por uma ação política que se firma nos elementos socioculturais. Significa re-enraizar para continuar enraizado ou poder criar novas raízes e mesclá-las com as já existentes, formatando espacialidades como condição para continuar (Re)Existindo. (PELÁ; MENDONÇA, 2010, p.54).

A (re)existência é uma ação política empreendida para contestar a ordem do capital, de maneira a manter e lutar, por exemplo, por seus territórios de vida e até mesmo a possibilitar a emancipação social.

Vale dizer que para nós não basta a definição de resistência enquanto a noção de fazer oposição a alguma coisa, como iniciamos esse assunto. Por isso, coadunamos com a definição proposta por Porto-Gonçalves (2006) já que dá visibilidade à ação dos sujeitos sociais e políticos. Entretanto, Pelá e Mendonça (2010) acrescentam a possibilidade de criação, mobilidade e da espacialidade desses sujeitos.

Dito isso, acrescentaríamos a essa definição de (re)existências, a ideia das experiências, para isso nos baseamos em Thompson (1981). A experiência possibilita um processo de negação, oposição, mas também de mediações, formação de identidade. 
Conforme Thompson (1981) a experiência (social e histórica) é um conceito mediador entre cultura e não cultura, entre ser social e consciência social.

Portanto, o conceito de (re)existir/(re)existência deve dar conta de compreender os sujeitos sociais e políticos enquanto sujeitos ativos e propulsores de ação, criação e experiências cotidianas de outras formas de ser/existir/viver/conviver/resistir em seus espaços/territórios. Ou seja, as (re)existências e o território têm relação direta, afinal é pelas disputas e ações territoriais que os sujeitos atuam e (re)existem.

Neste sentido, não podemos deixar de mencionar as ações de (re)existências e formas alternativas de mobilização e organização dos sujeitos pescadores e pescadoras artesanais frente ao modelo hegemônico do capital, que no setor pesqueiro atualmente atende pelo nome de aquicultura empresarial.

É preciso estar atento às diferentes estratégias e formas de (re)existir, seja mediante as experiências cotidianas de existir, de sua autonomia de trabalhar e produzir, ou por suas ações em movimentos sociais.

Os pescadores e as pescadoras artesanais tecem diferentes formas de (re)existências, seja na dimensão social, cultural, e, a exemplo das festas tradicionais em comemoração ao padroeiro desses trabalhadores, há ainda a plasticidade laboral, na qual muitos alteram a atividade pesqueira com outras atividades rurais ou urbanas. Existem ainda as mobilizações feitas através dos movimentos sociais. No Brasil, hoje, sem dúvida um exemplo característico de movimento social desses sujeitos é o Movimento de Pescadores e Pescadoras Artesanais do Brasil (MPP). Este movimento visa representar

[...] as categorias de pescadores artesanais que vêm no modelo de desenvolvimento historicamente excludente [...] e atualmente impulsionado, [...] pelo governo, nos últimos anos, via reestruturação produtiva nos moldes da aquicultura, a principal ameaça de seus modos de reprodução da vida. (WOJCIECHOWSKI, 2014, p.51-52)

O MPP como também outros movimentos estão atentos à atual conjuntura e estão reivindicando seus direitos. Como exemplo desse processo, foi lançado em junho de 2012 a Campanha pela Regularização dos Territórios das Comunidades Artesanais no país, que busca coletar a assinatura de pelo menos $1 \%$ do eleitorado brasileiro para que o projeto de lei de iniciativa popular possa ser encaminhado ao Congresso Nacional e garanta o direito ao território dessas comunidades. 
Outra importante expressão de (re)existência e organização se dá mediante as organizações e associações de moradores, comunidades tradicionais, em escala local, tais como a do Cumbe, Fortim e Canavieira ${ }^{8}$, todas localizadas no litoral sul do Ceará, e que lutam constantemente contra o avanço destrutivo da carcinicultura, que implica prejuízos substanciais a toda comunidade. As mulheres, em especial, nessas comunidades têm sido as mais diretamente impactadas pela carcinicultura, mas também têm sido através delas que as mobilizações têm ocorrido, permanecendo, e disputando diferentes espaços de debates e possibilitando a conquista de direitos.

Portanto, nota-se que a (re)existência dos pescadores e pescadoras artesanais e demais comunidades tradicionais envoltas neste processo, no Brasil, se faz presente e atuante, e todos eles estão sempre em luta e buscando a efetivação de seus direitos, ainda que constantemente haja mecanismos que visem à desestruturação e desarticulação do modo de vida, trabalho e território desses trabalhadores e trabalhadoras.

\section{Considerações finais}

Demonstramos a partir deste texto os dois modelos em disputa em torno do setor pesqueiro brasileiro. De um lado a atividade extrativista artesanal que aponta a fundamental relação entre os sujeitos, o seu trabalho e o território, que caracteriza uma atividade multidimensional e com particularidades e singularidades, próprias das relações e sujeitos que a exercem.

Do outro lado verifica-se a expansão territorial do capital aquícola empresarial, que tem demonstrado a força de um modelo de desenvolvimento e de controle próprio do agrohidronegócio, que está carregado de impactos e desafios à natureza, aos pescadores e pescadoras artesanais, às comunidades tradicionais, mas também à sociedade como um todo.

Ademais, apontamos algumas problemáticas, disputas e implicações que o modelo do capital aquícola empresarial tem causado em relação à lógica extrativista artesanal de trabalho desses sujeitos e de suas comunidades, que são constantes e historicamente vivenciadas em várias localidades brasileiras, mas nem por isso a importância dessa atividade e dos sujeitos deve ser desconsiderada e/ou negada de todo o processo histórico do setor de pescados nacional. 
Aliás, mesmo diante de uma série de conflitos e desafios a essa atividade e a esses(as) trabalhadores(as), ainda hoje eles são os responsáveis por boa parte da produção de pescados do país - por mais que não se tenham dados oficiais e atualizados dessas estatísticas, já que as mesmas estão apenas voltadas a registrar os dados da produção aquícola nacional -, e sabe-se que esses sujeitos prezam pela diversidade de espécies pescadas/coletadas, além desta atividade ser de fundamental importância na contribuição da soberania alimentar e na renda econômica de muitas famílias pesqueiras e extrativistas.

Do mesmo modo é preciso destacar que, assim como Silva (2015), compreendemos os pescadores e pescadoras (assim como as demais comunidades tradicionais) como sujeitos que existem no espaço e na história, que possuem relações de trabalho, vivências, sociabilidades, que precisam ser evidenciadas, o que a autora chamou de "geografias das existências", já que é preciso irmos para além das influências e dinâmicas de ordens e normas globais que abarcam o "território normado". Isto é, precisamos enfatizar e reconhecer os lugares e histórias que envolvem os territórios dessas comunidades tradicionais.

Nesse sentido, vale demarcar nosso entendimento de que não existe apenas um modelo de futuro ao setor de pescados no país, como tem sido proposto e ressaltado pelas políticas, pelo Estado e o capital. É preciso deixar registrado o nosso posicionamento de enfrentamento a essa proposta do capital, e a favor dos sujeitos sociais, pescadores e pescadoras artesanais, marisqueiras, ribeirinhos e demais comunidades tradicionais, que - ainda que historicamente sejam negados de reconhecimento - têm cotidianamente mostrado a força de suas lutas e (re)existências em defesa de seus direitos sociais, laborais, ambientais, políticos, econômicos, culturais e territoriais.

\section{Notas}

1 Sendo ainda dividida entre as práticas comerciais ou não, sejam atividades artesanais, industriais/empresariais, científica, amadora ou de subsistência.

${ }^{2}$ Vale dizer que esta atividade não é recente, já que existe há mais de 4 mil anos. Porém nas proporções e magnitudes com as quais vem sendo utilizada e posta em prática, sobretudo com uma ação particularizada pautada pelos ideários da produção sociometabólica do capital, essa sim é uma nova forma de pensar e fazer aquicultura, daí o nosso interesse.

${ }^{3} \mathrm{O}$ setor pesqueiro no país já passou por outras fases de transformações e ênfases de práticas produtivas, tais como as políticas com viés a industrialização do setor nos anos de 1960, com a Superintendência de Desenvolvimento da Pesca (SUDEPE), para maiores informações ver Moreno (2017).

${ }^{4} \mathrm{O}$ presente texto compreende parte das reflexões preliminares que estamos trabalhando em nossa tese de doutorado intitulada "A nova ordem sociometabólica da produção pesqueira no Brasil: as formas de 
controle do trabalho e da natureza versus as formas de resistências dos(as) trabalhadores(as)" que conta com o financiamento da FAPESP (Processo/Número: 2017/05923-0). Mas também em relação as motivações suscitadas pela disciplina "Teorias dos Territórios e da Questão Agrária", ministrada pelo professor Bernardo Mançano Fernandes, durante o primeiro semestre de 2017, nas dependências da UNESP/FCT - Presidente Prudente.

${ }^{5}$ Vale explicar, segundo May (2004), que o pesquisador não coleta dados, mas, sim, os produz, já que possui um papel ativo e de interferência nos dados. Ou seja, não há objeto de estudo que não seja intencional do pesquisador.

${ }^{6}$ Alguns trabalhos qualificam esse posicionamento, tais como: Thomaz Júnior (2009), Bezerra (2012) e Perpetua (2016).

7 "Reforma aquária" foi o título do artigo publicado no jornal Folha de São Paulo, em 26 de maio de 2013, no qual Marcelo Crivela, então ministro do MPA, destacou a importância de se valorizar e fortalecer a aquicultura no país, mediante a "democratização" do uso e acesso da água o que geraria emprego, renda e crescimento econômico ao país. Mas uma análise crítica desse processo demonstra na verdade não a democratização, mas sim a privatização e desregulamentação do acesso e uso da água com fins a produção aquícola por parte de empresas, em detrimento dos pescadores e ribeirinhos que há anos dependem desses recursos (SANTOS; ACIOLY, 2015; RAMALHO, 2014).

${ }^{8}$ Informações constatadas em nossos trabalhos de campo junto as referidas comunidades entre 2018 e 2019.

\section{Referências}

ALMEIDA, A. W. B. de. Terras de quilombos, terras indígenas, "babaçuais livres", "castanhais do povo", faxinais e fundos de pastos: terras tradicionalmente ocupadas 2. ${ }^{\mathrm{a}}$ ed, Manaus: PGSCA-UFAM, 2008, 192p.

\section{ASSESSORIA DE COMUNICAÇÃO DO CONSELHO PASTORAL DOS}

PESCADORES NACIONAL. Pescadores e pescadoras artesanais: arte e sustento em terras e águas brasileiras. 2015. Disponível em: <

http://peloterritoriopesqueiro.blogspot.com.br/2015/03/pescadores-epescadorasartesanais-arte.html>. Acesso em: 07 maio 2015.

BANCO DO BRASIL. Aquicultura e Pesca, volume 6. Desenvolvimento Regional Sustentável: série cadernos de propostas para atuação em cadeias produtivas. Brasília, 2010. 56p. Disponível em:

<http://www.bb.com.br/docs/pub/inst/dwn/Vol6AquiculturaPesca.pdf >. Acesso em:29/04/2016.

\section{BATISTA, P. I. S.; TUPINAMBÁ, S. V. A carcinicultura no Brasil e na América}

Latina: o agronegócio do camarão. 2004. Disponível em:

<http://www.rebrip.org.br/projetos/clientes/noar/noar/UserFiles/20/File/Outras\%20publi cacoes/carcinicultura.pdf>. Acesso em: 29 set. 2018.

BRASIL. Ministério da Pesca e Aquicultura. Boletim estatístico da pesca e aquicultura. Brasil 2010. Brasília, 2012. Disponível em:

<http://www.mpa.gov.br/files/docs/Informacoes_e_Estatisticas/Boletim\%20Estat\%C3\% ADstico\%20MPA\%202010.pdf>. Acesso em: 26 fev. 2015.

Ministério da Pesca e Aquicultura. Boletim estatístico da pesca e

aquicultura, 2011. Brasília, 2013. Disponível em: 
<http://www.mpa.gov.br/files/docs/Boletim_MPA_2011_pub.pdf >. Acesso em:26 fev. 2015 .

Ministério da Pesca e Aquicultura/SINPESQ. Registro Geral da Atividade Pesqueira. 2016. Disponível em: <http://sinpesq.mpa.gov.br/rgp_cms/>. Acesso em 28 mar. 2016.

BEZERRA, J. E. A fruticultura no Nordeste semiárido: internacionalização, conflitos territoriais e a precarização do trabalho. 2012, 376 f. Tese (Doutorado em Geografia). Programa de Pós-Graduação em Geografia, FCT/UNESP. Presidente Prudente, 2012.

BROL, J.; MOLINARI, D. Piscicultura no Paraná: rumo as 100 mil toneladas! Aquaculture Brasil. edição 5, 2017, p.38-45.

CARDOSO, E. S. Pescadores artesanais: natureza, território, movimento social. 2001, 143f. Tese (Doutorado em Geografia). Departamento de Geografia, Universidade de São Paulo, São Paulo, 2001.

CENTRO DE EXCELÊNCIA PARA O MAR BRASILEIRO. O Brasil e o mar no século XXI: Relatório aos tomadores de decisão do País. 2 ed., rev. e ampl. Niterói/RJ:BHMN, 2012, 540p.

COUTINHO, C. N. A hegemonia da pequena política. In: OLIVEIRA, F. de; BRAGA, R.; RIZEK, C. (Orgs.). Hegemonia às avessas: economia, política e cultura na era da servidão financeira. São Paulo: Boitempo, 2010.

D'ÁVILA, A. P. F.; TORRES, I. de L.; VARGAS, F. B. O trabalho dos pescadores da Colônia Z3. In: XX Congresso de Iniciação Científica, III Mostra Cientifica UFPEL. 2011. Disponível em: <http://www.ufpel.edu.br/cic/2011/anais/pdf/CH/CH_00828.pdf>. Acessado em: 05 maio 2012.

DIEGUES, A. C. Pescadores, camponeses e trabalhadores do mar. São Paulo: Ática, 1983.

FERNANDES, B. M. "O todo é a parte e a parte é o todo": a interação espaçosujeito. Revista de Geografia. São Paulo, vol.10, p.31-38, 1991.

Entrando nos territórios do Território. In: PAULINO, E. T.; FABRINI, J. E.

(Orgs.). Campesinato e Território em disputas. São Paulo: Expressão Popular, 2008.

Sobre tipologias de territórios. In: SAQUET, M. A.; SPOSITO, E. S. (Orgs.). Territórios e Territorialidades: teorias, processos e conflitos. São Paulo: Expressão Popular, 2009.

IBGE. Produção da pecuária municipal 2017. Rio de Janeiro, v.45, 2018. Disponível em: 
<https://biblioteca.ibge.gov.br/visualizacao/periodicos/84/ppm_2017_v45_br_informati vo.pdf $>$. Acesso em: 20 mar. 2019.

MARX, K. O capital: critica da economia política. São Paulo: Editora Nova Cultural, vol.1, 1996.

MAY, T. Pesquisa social: questões, métodos e processos. Porto Alegre: ArtMed, 2004.

MENDONÇA, M. R. Complexidade do espaço agrário brasileiro: o agrohidronegócio e as (re)existências dos povos cerradeiros. Terra Livre. São Paulo, ano 26, vol.1, n.34, 2010, p.189-202.

MENDONÇA, M. R.; MESQUITA, H. A. O agro-hidro-negócios no cerrado goiano: a construção das (re)existências. In: Encuentro Latinoamericano Ciencias Sociales y Represas, 1; Encontro Brasileiro Ciências Sociais e Barragens, 2. Anais... Salvador, 2007.

MEIRELES, A. J. de A.; QUEIROZ, L. de S. Certificação da carcinicultura no Brasil: o manto verde da destruição. Fortaleza: Instituto Terramar, 2011, 96p.

MÉSZÁROS, I. A necessidade do controle social. São Paulo: Ensaio, 1971.

Para além do capital: rumo a uma teoria da transição. Campinas: Ed. da UNICAMP; São Paulo: Boitempo, 2002.

MOREIRA, R. Geografia, ecologia, ideologia: a "totalidade homem-meio" hoje (espaço e processo do trabalho). In: MOREIRA, Ruy (Org.). Geografia: teoria e crítica: o saber posto em questão. Petrópolis: Vozes, 1982, p.197-214.

A geografia do espaço-mundo: conflitos e superação no espaço do capital. Rio de Janeiro: Consequência Editora, 2016, 235p.

MORENO, L. T. Os trabalhadores artesanais do mar em Ubatuba/SP: a dinâmica territorial do conflito e da resistência. 2016, 222f. Dissertação (Mestrado em Geografia) - Programa de Pós-Graduação em Geografia, Universidade Estadual Paulista, Presidente Prudente. 2017.

PORTO-GONÇALVES, C. A globalização da natureza e a natureza da globalização. Rio de Janeiro: Civilização Brasileira, 2006. 461p.

OLIVEIRA, J. da S. A participação dos movimentos sociais na disputa pela água no Pontal do Paranapanema. 2011, 110f. Trabalho de Conclusão de Curso (Bacharelado em Geografia) - Universidade Estadual Paulista, Presidente Prudente, 2011.

OLIVEIRA, J. da S. Políticas aquícolas no Pontal do Paranapanema e o controle privado da água. 2014, 146f. Dissertação (Mestrado em Geografia). Programa de PósGraduação em Geografia, Universidade Estadual Paulista, Presidente Prudente, 2014. 
PELÁ, M.; MENDONÇA, M. R. Cerrado goiano: encruzilhada de tempos e territórios em disputa. In: PELÁ, M.; CASTILHO, D. (Orgs.). Cerrados: perspectivas e olhares. 2010. p.51-70.

PERPETUA, G. M. Encruzilhadas teórico-político-metodológicas nos estudos do trabalho: um diálogo entre a sociologia do trabalho, a história social do trabalho e a geografia do trabalho. Revista Pegada, Presidente Prudente, vol.17, n.1, 2016, p. 28-46. Disponível em: <http://revista.fct.unesp.br/index.php/pegada/article/view/4044/3424>. Acesso em: 24 out. 2016.

RAMALHO, C. W. N. “Ah, esse povo do mar!": um estudo sobre trabalho e pertencimento na pesca artesanal pernambucana. São Paulo: Polis - Campinas, SP: CERES (Centro de Estudos Rurais do IFCH - UNICAMP), 2006.

Estado, pescadores e desenvolvimento nacional: da reserva naval à aquícola. Ruris (campinas), volume 8, p.31-61, 2014.

Ideologia e Aquicultura: uma das faces da revolução azul. Contemporânea, vol. 5, n.2, p.521-544, 2015. Disponível em: $<$ http://www.contemporanea.ufscar.br/index.php/contemporanea/article/viewFile/344/1 50>. Acesso em: 20 out. 2018.

Trabalho, classe e ideologia: o caso da aquicultura no estado de Pernambuco, Brasil, s/d. Disponível em: <http://actacientifica.servicioit.cl/biblioteca/gt/GT18/GT18_Wellington_Ramalho.pdf>. Acessoem: 13 abr. 2015.

ROSS, E. A. Social Control: a survey of the foundations of order. London: Macmillan \& CO. 1901.

SANTOS, M. A Natureza do Espaço: Técnica e Tempo, Razão e Emoção. $4^{\mathrm{a}}$ edição. São Paulo: Editora da Universidade de São Paulo, 2004.

Metamorfoses do Espaço Habitado: fundamentos teóricos e metodológicos da geografia. $6^{\text {a }}$ edição. São Paulo: Editora da Universidade de São Paulo, 2012.

SANTOS, J. S.; ACIOLY, Y. A. A privatização das águas no contexto da contrarreforma do Estado brasileiro. Serv. Soc. Soc., São Paulo, n. 122, p. 250-274, 2015. Disponível em: <http://www.scielo.br/pdf/sssoc/n122/0101-6628-sssoc-1220250.pdf>. Acesso em: 3 jul. de 2017.

SAQUET, M. A. Abordagens e concepções de território. São Paulo: Expressão Popular. 2007. 200p.

Por una geografía de las territorialidades y las temporalidades: una concepción multidimensional orientada a la cooperación y el desarrollo territorial. La Plata: Universidad Nacional de La Plata. Facultad de Humanidades y Ciencias de la Educación. 2015. Disponível em: <http://www.libros.fahce.unlp. 
edu.ar/index.php/libros/catalog/book/48>. Acesso em: 02 jul. 2017.

SILVA, C. A. Política pública e território: passado e presente da efetivação de direitos dos pescadores artesanais no Brasil. Rio de Janeiro: Consequência, 2015, 130p.

SUSSEL, F. R. A tilápia vem se ajustando a novos cenários e regiões. In: Anuário da Pecuária Brasileira (Anualpec), 2010. Disponível em:

<http://www.pesca.sp.gov.br/Tilapia_2010.pdf>. Acesso em: 20 out. 2018.

THOMAZ JÚNIOR, A. Dinâmica geográfica do trabalho no século XXI (Limites explicativos, autocrítica e desafios teóricos). 2009, 997p. Tese (Livre Docência) Faculdade de Ciências e Tecnologia, Universidade Estadual Paulista, Presidente Prudente, 2009.

Degradação sistêmica do trabalho no agrohidronegócio no Brasil. In: XXIII ENGA: Encontro Nacional de Geografia Agrária - Ajuste espacial x soberania(s): a multiplicidade das lutas e estratégias de reprodução no campo. Anais... Sergipe, 2016.

THOMPSON, E. P. A miséria da teoria ou um planetário de erros: uma crítica ao pensamento de Althusser. Rio de Janeiro: Zahar editores, 1981.

WOJCIECHOWSKI, M. J. Uma leitura teórica da espacialidade, institucionalidade e escalaridade do estado desenvolvimentista brasileiro no âmbito da pesca. 2014, 151f. Dissertação (Mestrado em Planejamento e Gestão do Território). Pós-Graduação em Planejamento e Gestão do Território, Universidade Federal do ABC, Santo André, 2014.

Recebido em 07/05/2018.

Aceito para publicação em 15/07/2019. 